\title{
Correction to: Interoperable chemical structure search service
}

\author{
Miroslav Kratochvíl ${ }^{1,2}$, Jiří Vondrášek ${ }^{1}$ (D) and Jakub Galgonek ${ }^{1 *}$ (])
}

\section{Correction to: J Cheminform (2019) 11:45} https://doi.org/10.1186/s13321-019-0367-2

It was highlighted that the original article [1] contained an error in the last paragraph of the section 'Structure search using SPARQL', specifically in the radius of the used fingerprint. This Correction article shows the incorrect and correct paragraph of this section.

\section{Incorrect}

The returned similarity score is based on Jaccard similarity [18] of Morgan-style connectivity fingerprints [19] with a radius of up to 5 .

\section{Correct}

The returned similarity score is based on Jaccard similarity [18] of Morgan-style connectivity fingerprints [19] with a radius of up to 3 .

\begin{abstract}
Author details
${ }^{1}$ Institute of Organic Chemistry and Biochemistry of the CAS, Flemingovo náměstí 2, 16610 Prague 6, Czech Republic. ${ }^{2}$ Department of Software Engineering, Faculty of Mathematics and Physics, Charles University, Malostranské náměstí 25, 11800 Prague 1, Czech Republic.
\end{abstract}

Published online: 13 February 2020

\section{Reference}

1. Kratochvíl M, Vondrášek J, Galgonek J (2019) Interoperable chemical structure search service. J Cheminform 11:45. https://doi.org/10.1186/ s13321-019-0367-2

\section{Publisher's Note}

Springer Nature remains neutral with regard to jurisdictional claims in published maps and institutional affiliations. is not included in the article's Creative Commons licence and your intended use is not permitted by statutory regulation or exceeds the permitted use, you will need to obtain permission directly from the copyright holder. To view a copy of this licence, visit http://creativeco mmons.org/licenses/by/4.0/. The Creative Commons Public Domain Dedication waiver (http://creativecommons.org/publicdomain/ zero/1.0/) applies to the data made available in this article, unless otherwise stated in a credit line to the data. 